\title{
Sleep disorders in menopausal women
}

\author{
Abha Singh, Abha Daharwal, Avinashi Kujur* \\ Department of Obstetrics and Gynecology, Pt. J. N. M. Medical College, Raipur, Chhattisgarh, India
}

Received: 29 April 2017

Revised: 15 May 2017

Accepted: 17 May 2017

\section{* Correspondence:}

Dr. Avinashi Kujur,

E-mail: avinashikujur@gmail.com

Copyright: (c) the author(s), publisher and licensee Medip Academy. This is an open-access article distributed under the terms of the Creative Commons Attribution Non-Commercial License, which permits unrestricted non-commercial use, distribution, and reproduction in any medium, provided the original work is properly cited.

\section{ABSTRACT}

Background: Sleep disturbance is one of frequent sign and symptom encountered in post-menopausal women. It affects the quality of the life and may lead to depression in some women. Objective of present study was to find out the prevalence of sleep disorder in post-menopausal women

Methods: Prospective study done on the post-menopausal women coming to Gynaecology OPD of Dr Bheem Rao Ambedkar Hospital, Raipur. This study was a prospective cross sectional observational study, conducted in the outpatient department of Obstetrics and Gynecology from $1^{\text {st }}$ August 2016 to $31^{\text {st }}$ January 2017. It included 500 women of postmenopausal age. A detail Performa was provided to assess sleep patterns and disorders associated with it. All the data was analysed using chi square test

Results: The prevalence of sleep disturbances was $29.58 \%$. Home makers were affected more in comparison to working women, $71,43 \%$ women had problems in initiating sleep. About 2/3rd women in the study group developed insomnia within 5 years of menopause, whereas $1 / 3$ rd took more than 7 years to develop insomnia. Co morbidities were present in $48 \%$ women. Our women have mean age of menopause around 45 years.

Conclusions: Sleep disorders are common, with prevalence of $29.5 \%$ in menopausal women in present study. It significantly causes psychosocial problems in women. There is need for it to be asked for and to be treated promptly.

Keywords: Co-morbidities, Insomnia, Postmenopausal women, Sleep disturbances

\section{INTRODUCTION}

Sleep disorders is one of the common symptoms and signs of menopausal transition. It may either affect the initiation of sleep or its maintenance. Patients afflicted with sleep disorders may have a wide variety of complaints, the majority of which are, generally, nonspecific.

It is therefore critically important that providers caring for these patients should be well-versed in the appropriate work-up. ${ }^{1}$ Because sleep disorders are affect a high proportion of the population and are known to be correlated with decreased wellbeing and productivity, more detailed national surveys are necessary to provide relevant information to develop approaches to prevention and treatment. ${ }^{2}$ Its cause has been a matter of enigma. Researchers have tried to link it to lower oestrogen level, vasomotor symptoms, existing diseases in the aged women and lifestyle. Whether the cause is hormonal or age related or genetic, is still largely unknown.

\section{METHODS}

This study was a prospective cross sectional observational study, conducted in the outpatient department of Obstetrics and Gynaecology from $1^{\text {st }}$ August 2016 to $31^{\text {st }}$ January 2017. It included 500 women 
of postmenopausal age. Menopausal status was determined by menstrual history, surgical history, and use of hormone replacement therapy. Sleep quality was subjectively measured. A detail Performa was provided to assess sleep patterns and disorders associated with it. All the data was analyzed using chi square test.

\section{RESULTS}

The prevalence of sleep disturbances was $29.58 \% . \%$ ). Our women have mean age of menopause around 45 years. $14.29 \%$ women suffering from sleep disorder had early menopause.

\section{Table 1: Characteristics of menopause.}

\begin{tabular}{|c|c|}
\hline Characteristics of menopause & \\
\hline $\begin{array}{l}\text { Mean age of menopause in women } \\
\text { under study }\end{array}$ & 45.45 years \\
\hline Women with natural menopause & $76.19 \%$ \\
\hline Women with surgical menopause & $23.81 \%$ \\
\hline $\begin{array}{l}\text { Women with early menopause at }<40 \\
\text { years }\end{array}$ & $14.29 \%$ \\
\hline
\end{tabular}

Homemakers $(71.43 \%)$ were affected more in comparison to working women $(28.57 \%)$. Majority of the women $(76.19 \%)$ with sleep disorder had attained menopause naturally whereas $23.81 \%$ women had surgical menopause.

Table 2: The epidemiological factors associate with sleep disorders.

\begin{tabular}{|l|l|}
\hline Epidemological factors & Percentage \\
\hline Urban & 38.09 \\
\hline Rural & 61.91 \\
\hline Illiterate & 57.14 \\
\hline Middle school & 19.04 \\
\hline High School & 04.76 \\
\hline Postgraduate & 19.06 \\
\hline Home makers & 71.43 \\
\hline Working & 28.57 \\
\hline
\end{tabular}

$71.43 \%$ women had problems in initiating sleep. About 2/3rd women in the study group developed insomnia within 5 years of menopause, whereas $1 / 3$ rd took more than 7 years to develop insomnia.

Table 3: Frequency of insomnia.

\begin{tabular}{|ll|}
\hline Frequency & Percentage \\
\hline 65 /month & 23.82 \\
\hline $6-10$ /month & 33.2 \\
\hline$>10$ / month & 42.86 \\
\hline
\end{tabular}

Co morbidities were present in $48 \%$ women. Most common co morbidity associated was hypertension (38\%).About $81 \%$ women were suffering from joint pains, $38.09 \%$ women complaint of developing forgetfulness and $9.52 \%$ women had depression. Assessment of quality of life revealed that only $30 \%$ women rate it satisfactory. Despite this less than $1 \%$ women were taking medical advice and were on medication.

Table 4: Associated co morbidities.

\begin{tabular}{|ll|}
\hline Conditions & Incidence \\
\hline Hypertension & $38 \%$ \\
\hline Diabetes mellitus & $9.52 \%$ \\
\hline Mood disorders & $38 \%$ \\
\hline Hot flashes & $23.8 \%$ \\
\hline Joint pain & 80.95 \\
\hline Depression & 9.52 \\
\hline Forgetfulness & 38.09 \\
\hline
\end{tabular}

\section{DISCUSSION}

We have done a subjective study on 500 menopausal women in an effort to find out its associating factors. The management of the problem definitely reduces the suffering of women and gives them fair quality of life. Life style modifications perhaps offer a better option than sleep medications.

The characteristics associated with menopause in the women are shown in Table 1. Our women seem to have menopause around 45 years. Not a single woman had a late menopause ( $>55$ years).

Our study in accordance with the study by Octavian who also showed that insomnia is more frequent in homemakers and retired individuals. ${ }^{1}$

In a Brazilian study insomnia was seen in $40 \%$ women as compared to men having only $25 \%$ incidence $^{2}$. Advancing age and menopause contribute significantly towards sleep disorders. In our study $71.43 \%$ women suffered from initiating sleep, while the rest of them had problem in maintenance of sleep. About $2 / 3^{\text {rd }}$ women in the study group developed insomnia within 5 years of menopause, whereas $1 / 3^{\text {rd }}$ took more than 7 years to develop insomnia.

The prevalence of sleep disorders was found to be $29.5 \%$. Eichling et al have found the prevalence of $25-50 \%$ in postmenopausal women in comparison to $15 \%$ in general population. ${ }^{3}$ The subjective complaint of poor sleep may not be necessarily related to electrophysiological disturbances. $^{4}$

Vasomotor symptoms are frequently seen in menopausal women. Kravitz et al have shown the same in a community based survey. ${ }^{5}$ In another population based study from Taiwan, hot flashes have been found to be associated with anxiety and depression. ${ }^{6}$ Some studies have shown that vasomotor symptoms are the main culprits for insomnia in women ${ }^{7}$.Thurston et al have shown that sleep may be affected even in absence of vasomotor symptoms. ${ }^{8}$ 
Table 4 shows the associated co morbidities, which may be age or life style related. Studies have pointed associated medical conditions and insomnia., ${ }^{9,10}$

Self-rated score for quality of life due to disturbed sleep was found more in women who had depression. Similar association was noted in a study by Myra et al. ${ }^{11}$

\section{CONCLUSION}

Sleep disorders are common, with prevalence of $29.5 \%$ at menopausal women in our study. It significantly causes psychosocial problems in women. There is need for it to be asked for and to be treated promptly.

\section{ACKNOWLEDGMENTS}

The authors are thankful to all the women included in the study, faculty and technical staff of department of Obstetrics and Gynecology, Dr. BRAM Hospital, Pt. J. N. M. Medical College, Raipur (C.G.) India, for their cooperation and support during the entire study period.

\section{Funding: No funding sources}

Conflict of interest: None declared

Ethical approval: The study was approved by the Institutional Ethics Committee

\section{REFERENCES}

1. Loachmescu OC. Contemporary sleep medicine for physicians. Publisher Bentham Science. 2011:14-40.

2. Bittencourt LR, Santos-Silva R, Taddei JA, Andersoen ML, de Mello MT, Tufik S. Sleep complaints in the adult Brazilian population: a national survey base on screening questions. Clin Sleep Med. 2009;5(5):459-63.

3. Eichling PS, Jyotsana Sahni J. Menopause related sleep disorders. J Clin Sleep Med. 2005;1(3):291300.
4. Young T, Rabago D, Zgerske A, Austin D, Laurel F. Objective and subjective sleep quality in premenopausal, perimenopausal and postmenopausal women in Wisconsin Sleep Cohort Study. Sleep. 2003;26:667-72.

5. Kravitz HM, Ganz PA, Bromberger J, Powell LH, Sutton-Tyrrell K, Meyer PM. Sleep difficulty in women at midlife: a community survey of sleep and the menopausal transition. Menopause. 2003;10(1):19-28.

6. Juang KD, Wang SJ, Lu SR, Lee SJ, Fuh JL. Hot flashes are associated with psychological symptoms of anxiety and depression in peri-and post-but not premenopausal women. Maturitas. 2005;52(2):11926.

7. Kroneuberg F. Menopausal hot flashes: a review of physiology and bio sociocultural perspective on method of assessment. J Nutr. 2010;140:1380s-5s.

8. Thurston RC, Chang Y, Mancuso P, Matthews KA. Adipokines, adiposity, and vasomotor symptoms during the menopause transition: findings from the Study of Women's Health Across the Nation. Fertil Steril. 2013;100(3):793-800.

9. Joffe H, Massler A, Sharkey KM. Evaluation and management of sleep disturbance during the menopause transition. In Seminars in Reprod Med. 2010;28:404-21.

10. Kravitz HM, Zheng H, Bomberger JT, Buysee DJ, Owens J, Hall MH. An actigraphy study of sleep and pain in midlife women: the study of Women's Health across nation sleep study. Menopause. 2015;22:7108.

11. Hunter M, Battersby R, Whitehead M. Relationships between psychological symptoms, somatic complaints and menopausal status. European Menopause J. 1986;8(3)217-28.

Cite this article as: Singh A, Daharwal A, Kujur A. Sleep disorders in menopausal women. Int J Reprod Contracept Obstet Gynecol 2017;6:2289-91. 